\title{
Are bipolar disorder and schizophrenia neuroanatomically distinct? An anatomical likelihood meta-analysis
}

\author{
Kevin $\mathrm{Yu}^{1+}$, Charlton Cheung ${ }^{1+}$, Meikei Leung ${ }^{1}$, Qi Li ${ }^{1,2}$, Siew Chua ${ }^{1,2,3}$ and Gráinne McAlonan ${ }^{1,2,3 *}$ \\ 1 Department of Psychiatry, Li Ka Shing Faculty of Medicine, The University of Hong Kong, Pokfulam, Hong Kong \\ 2 Centre for Reproduction Development and Growth, The University of Hong Kong, Pokfulam, Hong Kong \\ ${ }^{3}$ State Key Laboratory for Brain and Cognitive Sciences, The University of Hong Kong, Pokfulam, Hong Kong
}

\section{Edited by:}

Chris Rorden, Georgia Insitute of

Technology, USA

\section{Reviewed by:}

Peter Sörös, University of Western

Ontario, Canada

Susan Whitfield-Gabrieli,

Massachusetts Institute of Technology

USA

\section{${ }^{*}$ Correspondence:}

Gráinne McAlonan, Department of

Psychiatry, Li Ka Shing Faculty of

Medicine, The University of Hong

Kong, Pokfulam, Hong Kong.

e-mail:mcalonan@hkucc.hku.hk

${ }^{\dagger}$ Kevin Yu and Charlton Cheung have contributed equally to this work.

\begin{abstract}
Objective: There is renewed debate on whether modern diagnostic classification should adopt a dichotomous or dimensional approach to schizophrenia and bipolar disorder. This study synthesizes data from voxel-based studies of schizophrenia and bipolar disorder to estimate the extent to which these conditions have a common neuroanatomical phenotype. Methods: A post-hoc meta-analytic estimation of the extent to which bipolar disorder, schizophrenia, or both conditions contribute to brain gray matter differences compared to controls was achieved using a novel application of the conventional anatomical likelihood estimation (ALE) method. 19 schizophrenia studies (651 patients and 693 controls) were matched as closely as possible to 19 bipolar studies (540 patients and 745 controls). Result: Substantial overlaps in the regions affected by schizophrenia and bipolar disorder included regions in prefrontal cortex, thalamus, left caudate, left medial temporal lobe, and right insula. Bipolar disorder and schizophrenia jointly contributed to clusters in the right hemisphere, but schizophrenia was almost exclusively associated with additional gray matter deficits (left insula and amygdala) in the left hemisphere. Limitation: The current meta-analytic method has a number of constraints. Importantly, only studies identifying differences between controls and patient groups could be included in this analysis. Conclusion: Bipolar disorder shares many of the same brain regions as schizophrenia. However, relative to neurotypical controls, lower gray matter volume in schizophrenia is more extensive and includes the amygdala. This fresh application of ALE accommodates multiple studies in a relatively unbiased comparison. Common biological mechanisms may explain the neuroanatomical overlap between these major disorders, but explaining why brain differences are more extensive in schizophrenia remains challenging.
\end{abstract}

Keywords: bipolar, schizophrenia, meta-analysis, voxel-based, gray matter

\section{INTRODUCTION}

The Kraepelinian dichotomy between schizophrenia and bipolar disorder, otherwise classically referred to dementia praecox and manic-depressive insanity respectively, has sustained a recent and vigorous onslaught (Heckers, 2008). This debate echoes Kraepelin's own prescient observation that "No experienced psychiatrist will deny that there is an alarmingly large number of cases in which it seems impossible, in spite of the most careful observation, to make a firm diagnosis"(Angst and Gamma, 2008). Increasingly, the lines of scientific evidence converge toward dimensional constructs or fused constructs, as opposed to purely categorical ones. The rationale for this is that diagnostic classifications make a priori assumptions about the illness entity, precluding a truly heuristic approach to etiological and treatment advances. For example, researchers typically compare a group of patients with bipolar disorder or schizophrenia with healthy controls and adopt a disease classification system such as ICD10 or DSM IV. However, both conditions are intimately related, with shared genetic determinants (Lichtenstein et al., 2009) and common polygenic variants, as confirmed by the International Schizophrenia Consortium (ISC) in a genome-wide association study of 3,322 Europeans (International Schizophrenia Consortium et al., 2009). Thus, epidemiological characteristics, family studies, and overlapping genetic linkages together support shared genetic risk factors in bipolar and schizophrenia (Berrettini, 2003) and there is additional new evidence showing similar changes in gene expression in both conditions (Shao and Vawter, 2008). Llewellyn (2009) has suggested that bipolar disorder is in fact part and parcel of schizophrenia and constitutes an "autopoietic response" to restore order in schizophrenics (Llewellyn, 2009). The opposing position is that bipolar disorder and schizophrenia are separate disorders which happen to trigger the same, general cognitive deficits (Bora et al., 2009).

Neuroimaging studies of schizophrenia and bipolar disorder typically provide considerable data on the brain endophenotype of psychosis. However the extent to which bipolar disorder is considered separately from schizophrenia and other psychoses varies. For example, schizophrenia usually includes psychotic symptoms such as hallucinations, delusions, and thought disorder, as well as "negative" symptoms such as flatness of affect, poverty of speech, or loss of motivation. The diagnosis of schizophrenia excludes significant mood disorder. In contrast bipolar disorder is characterized by prominent mood symptoms and may or may not involve psychosis. Brain imaging studies in schizophrenia generally report lower brain volume, lateral ventricular enlargement, frontal, and lower 
volumes in temporal, limbic, and subcortical regions (Chua and McKenna, 1995; Gur et al., 1999; McCarley et al., 1999; Wright et al., 2000; Chua et al., 2007) and meta-analyses of "voxel-based morphometry" (VBM) studies which quantify brain differences at each voxel or "volume element" in brain, confirm fronto-striatal temporal and insula deficits are already evident at first presentation of schizophrenia (Ellison-Wright et al., 2008; Chan et al., 2009; Leung et al., 2009). Some groups report brain differences that appear to be specific to schizophrenia (Harvey et al., 1994; Pearlson et al., 1997; Zipursky et al., 1997; Altshuler et al., 2000; Hirayasu et al., 2001; McDonald et al., 2005), while others find similar changes in bipolar disorder and schizophrenia (Friedman et al., 1999; Lim et al., 1999; Velakoulis et al., 1999; Janssen et al., 2008).

The literature is complicated by issues of sample heterogeneity and study design. In some studies the conditions have been examined together as a generic psychosis category (McIntosh et al., 2004, 2006; McDonald et al., 2005; Janssen et al., 2008), with diagnostic categories explored post-hoc. For example, Janssen et al. (2008) found left medial frontal gray matter deficits in both conditions with left middle frontal deficits only in schizophrenia (Janssen et al., 2008). Others have separately compared schizophrenia and bipolar groups with neurotypical controls and reported an extensive system of gray matter deficits through fronto-temporal-thalamic and cerebellar regions in schizophrenia, and no significant gray matter abnormalities in the bipolar group (McDonald et al., 2005). Most recently, Bora et al. (2010), conducted a meta-analysis on Bipolar Disorder using signed differential mapping (Bora et al., 2010), an alternative voxel-based meta-analytic approach designed to represent both positive and negative differences in the same summary map. They found the condition involved anatomical differences compared to controls in bilateral insula, inferior frontal, and left anterior cingulate, and their results mostly coincided with another meta-analysis conducted by Ellison-Wright and Bullmore (2010) using anatomical likelihood estimation (ALE) to qualitatively compare gray matter differences in schizophrenia and bipolar disorders relative to controls (Ellison-Wright and Bullmore, 2010). In the latter study lower gray matter volume in anterior cingulate and insular regions overlapped when the meta-analysis summary map from studies comprising a total 2,058 patients with schizophrenia was overlaid on the meta-analysis summary map generated from studies of a total 366 patients with bipolar disorder. This pattern was retained when a subsample analysis of 13 studies of both conditions were analyzed and provided a good description of areas commonly affected by schizophrenia. Although gender balance was attempted in this sub-analysis, other confounders such as illness chronicity and age may also have affected the results. Moreover, what is missing from the literature is an estimation of the extent to which brain regions implicated in either disorder, are more likely to be affected by schizophrenia or bipolar disorder.

A recognized difficulty with the neuroimaging literature has been the many more VBM studies of schizophrenia than bipolar disorder published (Ellison-Wright and Bullmore, 2010). Since the initial meta-analyses of voxel-based studies of bipolar disorder were carried out, a number of new studies on bipolar disorder have been published, substantially increasing the number of bipolar patients sampled. This offers a timely opportunity to carry out a meta-analysis which quantifies the likelihood that schizophrenia or bipolar disorder is responsible for differences in regional brain anatomy. To prevent schizophrenia studies biasing the analysis, and to attempt to minimize confounders, a one-on-one matching approach was adopted to pair up individual bipolar studies with a corresponding schizophrenia study. The matching variables used were duration of illness, mean age of patients, mean age of control, number of patients, and number of controls.

Anatomical likelihood estimation was introduced by Turkeltaub et al. (2002) as "Activation Likelihood Estimation", in which it was used to study the functional neuroanatomy of single-word reading in healthy individuals. Despite bearing different nomenclature, ALE and Activation Likelihood Estimation share the same statistical approach. Essentially, in activation likelihood estimation, the data entered into analyses are of significant BOLD activation, whereas in anatomical likelihood they concern significant volume differences.

\section{MATERIALS AND METHODS DATA SEARCH}

A search was carried out using Pubmed, Scopus, and PsycINFO databases with the keywords: bipolar, MRI, VBM, voxel, voxel based morphometry, and statistical parametric mapping (SPM). A branch search was conducted from the retrieved studies. Studies comparing groups with bipolar patients, to controls balanced for IQ, gender, and handedness were selected. The studies must have been peer-reviewed and published in the English language. Moreover, they must have used voxel-based imaging methods, and reported co-ordinates in $3 \mathrm{D}$ stereotactic space. Studies restricted to males/females or children/adults were included in the initial screening. Where data from an earlier study formed part of another study, the largest was selected. Initially, $23 \mathrm{VBM}$ bipolar studies were found meeting our criteria (Bruno et al., 2004; Doris et al., 2004; Lochhead et al., 2004; Lyoo et al., 2004; McIntosh et al., 2004; Dickstein et al., 2005; Farrow et al., 2005; McDonald et al., 2005; Nugent et al., 2006; Adler et al., 2007; Chen et al., 2007; Yatham et al., 2007; Haldane et al., 2008; Janssen et al., 2008; Scherk et al., 2008; Almeida et al., 2009; Ha et al., 2009; Kempton et al., 2009; Stanfield et al., 2009; Li et al., 2010; Tost et al., 2010). However, three of these studies could not be included since they reported no gray matter volume differences between patients and controls (Bruno et al., 2004; McDonald et al., 2005; Scherk et al., 2008), and this cannot be accommodated in ALE. Two of the studies included comprised patients of bipolar type 1 and 2 (McIntosh et al., 2004; Ha et al., 2009), while all other studies reported patients with type 1 disorder. Four studies (McIntosh et al., 2004; Farrow et al., 2005; McDonald et al., 2005; Janssen et al., 2008) compared volumetric changes between bipolar and schizophrenia. Co-ordinates on bipolar disorder from three of these studies (McIntosh et al., 2004; Farrow et al., 2005; Janssen et al., 2008), were included in the analysis as one study only reported co-ordinates describing schizophrenia (McDonald et al., 2005).

Another search was conducted to look for "matching" studies which addressed schizophrenia. Because the majority of bipolar studies comprised patients who had an illness duration of over 5 years, and were medicated, the search extended to allow matching using the keywords: schizophrenia, chronic schizophrenia, psychosis, medicated, medication, MRI; found 54 schizophrenia 
studies (Wright et al., 1999; Hulshoff Pol et al., 2001; PaillereMartinot et al., 2001; Sigmundsson et al., 2001; Wilke et al., 2001; Ananth et al., 2002; Job et al., 2002; Kubicki et al., 2002; Shapleske et al., 2002; Suzuki et al., 2002; Marcelis et al., 2003; SalgadoPineda et al., 2003, 2004; Ha et al., 2004; Moorhead et al., 2004; Antonova et al., 2005; Giuliani et al., 2005; Honea et al., 2005; Jayakumar et al., 2005; McDonald et al., 2005; Neckelmann et al., 2006; Ohnishi et al., 2006; Whitford et al., 2006; Bassitt et al., 2007; Chua et al., 2007; Douaud et al., 2007; Kasparek et al., 2007, 2010; Kawasaki et al., 2007; Marti-Bonmati et al., 2007; Prasad et al., 2007; Schaufelberger et al., 2007; Tregellas et al., 2007; Yamada et al., 2007; Cooke et al., 2008; Garcia-Marti et al., 2008; Hirao et al., 2008; Koutsouleris et al., 2008; Meda et al., 2008; Meisenzahl et al., 2008; Venkatasubramanian et al., 2008; Wolf et al., 2008; Yoshihara et al., 2008; Benedetti et al., 2009; Euler et al., 2009; Herold et al., 2009; Lui et al., 2009a,b; Segall et al., 2009; Tomelleri et al., 2009; Witthaus et al., 2009; Xu et al., 2009). Of these studies, Antonova et al. (2005), Cooke et al. (2008), Farrow et al. (2005), Giuliani et al. (2005), and Janssen et al. (2008) included patients with schizoaffective disorder.

\section{ONE-TO-ONE MATCHING OF STUDIES}

The guidelines followed for matching were as follows:

1) Bipolar and schizophrenia studies were matched by mean duration of illness and mean age of the patients

2) If the duration of illness was not stated in the bipolar study, then the mean age of onset was matched

3) If a VBM study already compared bipolar disorder and schizophrenia, then information from both the bipolar and schizophrenia aspects of the study would be included, essentially it was considered to be "self-matched"

4) During matching, if there were two or more similar schizophrenia studies, the mean age of controls, number of patients, and number of controls were considered to obtain as close a match as possible.

5) If the bipolar study comprised patients experiencing their first episode of illness, then the matching schizophrenia study also contained first episode patients.

First episode was so defined by the authors of the original studies included in the analysis (the longest mean duration of illness reported was 7 months). Five of the selected schizophrenia studies comprised patients with schizoaffective disorders (Antonova et al., 2005; Farrow et al., 2005; Giuliani et al., 2005; Cooke et al., 2008; Janssen et al., 2008) - see Table 1.

\section{CONVERSION OF CO-ORDINATES TO TALAIRACH SPACE}

There were a total of 350 co-ordinates (184 for bipolar disorder, 166 for schizophrenia) extracted from the selected studies. Co-ordinates in Montreal Neurological Institute (MNI) format were transformed into the Talairach space (Talairach and Tournoux, 1988) using the "Lancaster transform," icbm2tal (Laird et al., 2010). Co-ordinates transformed to Talairach space using the 'Brett transformation', mni2tal, were transformed to the original MNI using mni2tal, and reconverted to Talairach using icbm2tal.

\section{DUAL DISORDER ALE QUANTIFICATION}

By convention, ALE is performed to study a single disorder based on the paradigm that co-ordinates that are close in proximity will form resultant 3D clusters while distant co-ordinates will be filtered out. Consequently, resultant clusters in ALE should map to regions most consistently reported across studies for any given disorder. These regions theoretically hold greater biological importance than areas appearing in a single study only. This is achieved by first, extracting co-ordinates representing brain differences from voxel-based studies of the same disorder to generate a map of gray matter of differences A "permutation test" is used to examine whether each voxel on the likelihood map is statistically significant (Turkeltaub et al., 2002) in the whole brain. The threshold to define significance is determined by the false-discovery rate (FDR) technique (Laird et al., 2005). Finally, neighboring voxels that are identified as significant are clustered together, and the smaller clusters are filtered to avoid noise in the ALE result.

In the present study, a map of gray matter differences relative to controls was compiled for each individual study selected for inclusion, and smoothed with a kernel of $8 \mathrm{~mm}$ full width at half maximum (FWHM). Eight millimeter was used because we found it to have the best balance between false positive control and optimal cluster size (if too small, FWHM could generate nonrepresentative "false positive" clusters, while if too large, it might limit anatomical resolution). The gray matter difference maps were then grouped according to their disorder type, and averaged into a mean map; thus, a mean map of bipolar and a mean map of schizophrenia were generated (see Figure 1). The mean maps were joined to create a total gray matter difference map, after which whole brain permutation testing $(10,000$ permutations) (Turkeltaub et al., 2002), and controlled FDR thresholding $(p<0.05)$ (Laird et al., 2005) was conducted. Clusters greater than $100 \mathrm{~mm}^{3}$ were reported in the final ALE image (Laird et al., 2009). These steps were conducted using our in-house ALE kernel (Leung et al., 2009) derived from the open source software available at http://csl.georgetown.edu/software/ (Turkeltaub et al., 2002). The "intensity" ratio of the mean disorder maps to the final ALE result at each resultant cluster was calculated. In all of the gray matter difference maps, the chance of finding gray matter differences was reflected by the voxel intensity. Suppose for a particular foci which has a voxel intensity of $x$ unit in the mean bipolar difference map and $y$ unit in the mean schizophrenia difference map, its corresponding intensity in the total gray matter difference map, and essentially the ALE result, would be $x+y$ unit. The 'intensity' ratio of the bipolar difference map and the ALE result for that foci would be $x: x+y$, which gives an estimation of the contribution of bipolar studies to the final ALE result (ALE kernel and customized scripts for Matlab and SPM5 available from the authors of request). Thus, for a particular cluster, a higher percentage contribution from one disorder meant there was a higher chance that foci derived from that disorder were localized around that cluster. In contrast, an equal contribution of $50 \%$ would indicate an equal chance of finding foci from either disorder within the cluster. Two separate ALE analyses were conducted for lower gray matter volume and gray matter excess in bipolar disorder and schizophrenia. 


\section{RESULTS}

\section{GRAY MATTER DEFICITS}

There were 17 resultant ALE clusters. Both disorders showed lower gray matter in the bilateral frontal gyrus, thalamus, left middle temporal gyrus, cingulate gyrus, and caudate (near the caudate head). Gray matter volume lower in the left amygdala and insula was driven almost exclusively by schizophrenia studies (see Figure 2 and Table 2).

\section{GRAY MATTER EXCESS}

There were six significant ALE clusters indicating gray matter excess in bipolar disorder and schizophrenia. Clusters with excess gray matter volume exclusively generated from bipolar disorder were identified in the tail of caudate bilaterally and right pre/post central gyrus. Volumetric enlargement of the left putamen were reported in both bipolar and schizophrenia studies. Larger left lentiform nucleus volume was also reported in schizophrenia, with larger left globus pallidus a feature of bipolar studies (see Figure 2 and Table 3 ).

\section{DISCUSSION}

This study further develops the ALE approach to compare voxelbased brain-imaging data from studies of schizophrenia and bipolar disorder (Ellison-Wright and Bullmore, 2010). We did this to evaluate the extent to which the gray matter phenotype overlapped in these disorders. This helped address, at the neuroanatomical level, whether these disorders were more similar (continuous) or different (dichotomous) to each other. We found that in numerous regions gray matter volume was lower in both schizophrenia and bipolar disorder relative to neurotypical controls. The brain regions involved included bilateral frontal cortex, thalamus, left middle temporal gyrus, cingulate, and caudate. Schizophrenia studies almost exclusively generated additional clusters of lower gray matter volumes in the left hemisphere (including amygdala, and insula).

In this analysis, studies of schizophrenia were carefully selected to match those of bipolar disorder. The gray matter deficits in temporal, medial parietal, prefrontal, thalamus, caudate, and insula regions attributable to schizophrenia studies reported here, generally agree with those identified in previous meta-analyses of schizophrenia which had different sampling criteria (Ellison-Wright et al., 2008; Chan et al., 2009; Leung et al., 2009). In contrast, the literature on bipolar disorder has been much sparser. To the best of our knowledge, all the voxel-based studies of bipolar disorder reporting co-ordinates of gray matter volume differences relative to controls have been included in the meta-analysis. Every attempt was made to ensure that the schizophrenia studies were, as far as possible, balanced in terms of exposure to medication and duration of illness, since these have been reported to contribute to a lack of consistency between region-of-interest (ROI) and VBM studies (Giuliani et al., 2005). For example, the mood stabilizer lithium is known to

Table 1 | Schizophrenia and bipolar disorder studies, paired for similar duration of illness, and age of patients.

\begin{tabular}{|c|c|c|c|c|c|c|}
\hline Bipolar studies (Bi) & Schizophrenia studies (Sc) & $\begin{array}{l}\text { Mean duration of } \\
\text { illness }(\mathrm{Bi} / \mathrm{Sc}) \\
\text { (years) }\end{array}$ & $\begin{array}{l}\text { Mean age of } \\
\text { patients (Bi/Sc) } \\
\text { (years) }\end{array}$ & $\begin{array}{l}\text { Mean age of } \\
\text { controls } \\
\text { (Bi/Sc) } \\
\text { (years) }\end{array}$ & $\begin{array}{l}\text { Sample } \\
\text { size } \\
(\mathrm{Bi} / \mathrm{Sc})(n)\end{array}$ & $\begin{array}{l}\text { Controls } \\
(\mathrm{Bi} / \mathrm{Sc})(n)\end{array}$ \\
\hline Adler et al. (2005) & Marcelis et al. (2003) & $8.7 / 8.5$ & $31.2 / 30.7$ & $30.5 / 35.5$ & $32 / 31$ & $27 / 27$ \\
\hline Adler et al. (2007) & Job et al. (2002) & $\mathrm{FE} / \mathrm{FE}^{1}$ & $19.9 / 21.4$ & $21.5 / 21.2$ & $33 / 34$ & $33 / 36$ \\
\hline Dickstein et al. (2005) & Yoshihara et al. (2008) & $3.3 / 1.2$ & $13.4 / 15.8$ & $13.3 / 15.8$ & $20 / 18$ & $20 / 18$ \\
\hline Doris et al. (2004) & Ananth et al. (2002) & $16.2 / 15.8$ & $38.1 / 37.8$ & $38.4 / 38.6$ & $11 / 20$ & $16 / 20$ \\
\hline Farrow et al. $(2005)^{2}$ & & $\mathrm{FE} / \mathrm{FE}^{1}$ & $17.5 / 19.7$ & 20.4 & $8 / 25$ & 22 \\
\hline Ha et al. (2009) & Hirao et al. (2008) & $10.4 / 10.6$ & $35.6 / 36.7$ & $36 / 35$ & $23 / 20$ & $23 / 20$ \\
\hline Haldane et al. (2008) & Ohnishi et al. (2006) & 16.3/19.3 & $42.7 / 44.2$ & $43.1 / 40.3$ & $44 / 47$ & $44 / 76$ \\
\hline Lochhead et al. (2004) & Benedetti et al. (2009) & $24.3 / 24.8 \mathrm{yrs} \mathrm{old}^{4}$ & $38.2 / 37.2$ & $36 / 35.1$ & $11 / 24$ & $31 / 20$ \\
\hline Lyoo et al. (2004) & Giuliani et al. (2005) & $18.6 / 21.6 \mathrm{yrs} \mathrm{old}^{4}$ & $38.3 / 39$ & $35.7 / 34.7$ & $39 / 41$ & $43 / 34$ \\
\hline McIntosh et al. (2004) $)^{2}$ & & $\mathrm{n} / \mathrm{a}$ & $36.9 / 40.2$ & 35.3 & $45 / 26$ & 49 \\
\hline Nugent et al. (2006) & McDonald et al. (2005) & 23/17.4 & $41.2 / 37.3$ & $38 / 39.3$ & $20 / 25$ & $65 / 52$ \\
\hline Stanfield et al. (2009) & Tomelleri et al. (2009) & $15.4 / 14.1$ & $36.4 / 39.7$ & $39 / 40.3$ & $66 / 70$ & $66 / 79$ \\
\hline Tost et al. (2010) & Antonova et al. (2005) & $15.9 / 16.8$ & $42.4 / 40.5$ & $42.2 / 33.7$ & $42 / 45$ & $42 / 43$ \\
\hline \multirow[t]{2}{*}{ Yatham et al. (2007) } & Herold et al. (2009) & $3.9 / 3.4$ & $36 / 28.4$ & $36 / 27.4$ & $15 / 18$ & $15 / 21$ \\
\hline & & Total: & $32.7 / 33.2$ & $32.2 / 32.0$ & $540 / 651$ & $693 / 745$ \\
\hline
\end{tabular}

${ }^{1}$ Both studies comprised patients experiencing their first episode (FE) of illness.

2Study was "self-matched" as it compared both bipolar disorder and schizophrenia.

${ }^{3}$ Whole schizophrenia group was used for comparison.

${ }^{4}$ Age of first onset used for matching. 


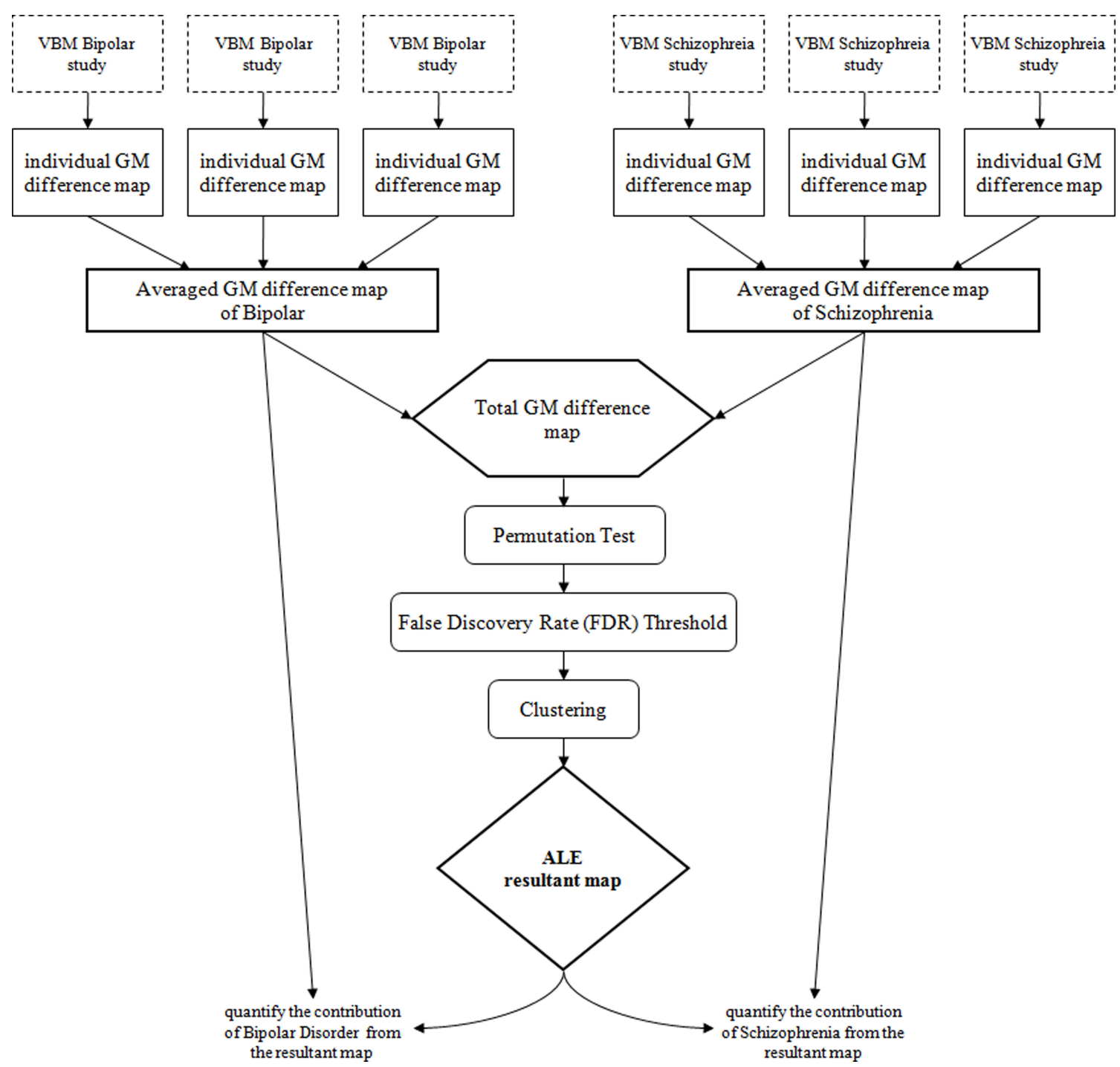

FIGURE 1 | Flow chart of dual disorder ALE quantification.

have neurotrophic effects leading to gray cortical volume increase either after just 4 weeks (Moore et al., 2000) or more chronically (Silverstone et al., 2003). Not only lithium but also sodium valproate and carbamazepine are regarded as neuroprotective agents since they regulate numerous factors involved in cell survival pathways, including cyclic adenine monophospate response elementbinding protein, brain-derived neurotrophic factor (BDNF), bcl-2, and mitogen-activated protein kinases (Bachmann et al., 2005). BDNF itself is necessary for neurotrophic signaling to regulate survival and function of neurons, synaptic plasticity and even the release of glutamate, GABA, dopamine, and serotonin (Du et al., 2003). However our analysis cannot speak directly to whether such neuroprotection is translated into the greater extent of gray matter excess in bipolar disorder observed in this analysis.

Findings from traditional ROI studies in schizophrenia fit reasonably well with our results and those from other ALE studies of schizophrenia. For example, there are reports of smaller amygdala (Joyal et al., 2003) and smaller insula (Crespo-Facorro et al., 2000; Kasai et al., 2003) in schizophrenia, although this is not always the case (for a fuller discussion see Leung et al., 2009). However, region of interest studies in bipolar disorder are more infrequent. Consistent with the present results, Drevets et al. (1997) reported smaller anterior cingulate in bipolar disorder (Drevets et al., 1997), while in contrast to the present results, Altshuler et al. (2000) reported that the amygdala is enlarged in bipolar disorder (Altshuler et al., 2000) and this finding was later supported by a ROI based meta-analysis(Arnone et al., 2009).

A number of past studies have directly compared schizophrenia and bipolar disorder. In general, gray matter deficits are more consistently reported in schizophrenia. Friedman et al. (1999), found comparable deficits in schizophrenia and bipolar disorder (Friedman et al., 1999), but Lim et al. (1999) reported that deficits were more pronounced in schizophrenia (Lim et al., 1999). Other investigations have found that gray matter deficits are selectively 


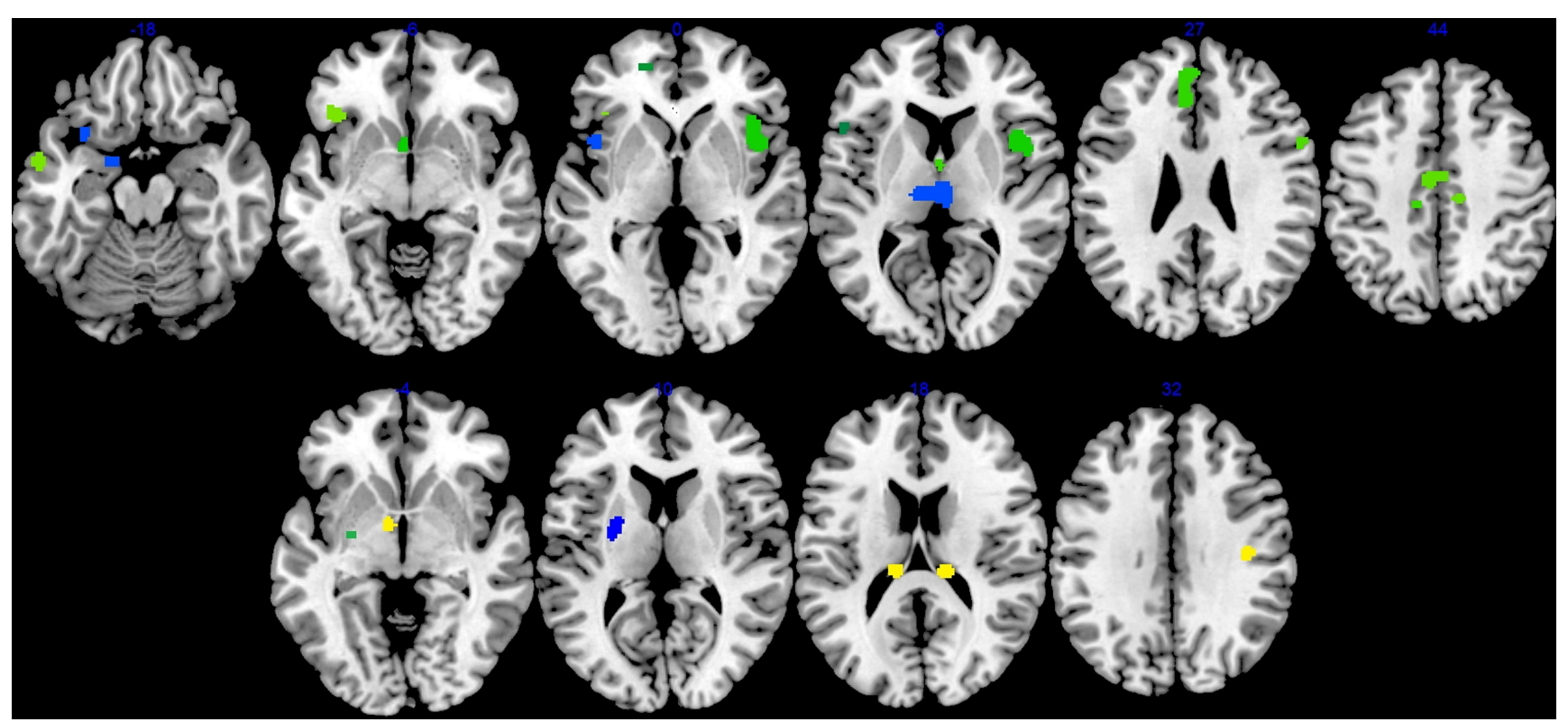

FIGURE 2 | Cerebral gray matter volume deficits (top panel) and excess (bottom panel) in schizophrenia and bipolar disorder compared with healthy controls. Blue clusters were driven mainly (greater than $80 \%$ distribution) by schizophrenia studies, while yellow were by bipolar studies. Green clusters were contributed by studies of both disorders (less than $80 \%$ distribution in either condition). Left side of brain is on left side of the panel.

Table 2 | Percentage distribution of significant ALE clusters by disorder in reduced gray matter volume.

\begin{tabular}{lllll}
\hline Cluster & Cluster center & Location & Bipolar (\%) & Schizophrenia (\%) \\
\hline 1 & $(-44.47,11.14,0.59)$ & Left insula (BA 13) & 4.5 & 95.5 \\
2 & $(-16.81,-0.46,-18.49)$ & Left uncus/amygdala (BA 34) & 4.6 & 95.4 \\
3 & $(-32.22,15.18,-17.82)$ & Left inferior frontal gyrus (BA 47) & 15.7 & 15.9 \\
4 & $(-2.92,-17.35,8.04)$ & Thalamus (anterior nuclei) & 25.8 & 84.3 \\
5 & $(-40.71,20.99,13.57)$ & Left inferior frontal gyrus (BA 45) & 35.4 & 74.2 \\
6 & $(-51.89,18.15,5.69)$ & Left inferior frontal gyrus (BA 45) & 39.9 & 64.6 \\
7 & $(-18.74,51.59,1.44)$ & Left superior frontal gyrus (BA 10) & 53.8 & 60.1 \\
8 & $(-3.52,8.65,-5.25)$ & Left caudate (caudate head) & 55.2 & 46.2 \\
9 & $(43.1,11.78,4.8)$ & Right insula/precentral gyrus (BA 44) & 60.8 & 44.8 \\
10 & $(-4.09,45,24.08)$ & Left medial frontal gyrus (BA 9) & 62.2 & 39.2 \\
11 & $(-0.61,-1.7,10.85)$ & Thalamus (medial dorsal nucleus) & 62.9 & 37.8 \\
12 & $(-13.06,-22.62,41.91)$ & Left cingulate gyrus (BA 31) & 66.3 & 37.1 \\
13 & $(57.5,9.82,26.4)$ & Right inferior frontal gyrus (BA 9) & 69 & 33.7 \\
14 & $(0.04,-7.61,46.39)$ & Left paracentral lobule (BA 31) & 70.8 & 31 \\
15 & $(10.81,-20.78,46.29)$ & Right medial frontal gyrus (BA 6) & 74.5 & 29.2 \\
16 & $(-57.54,0.11,-21.2)$ & Left middle temporal gyrus (BA 21) & 74.8 & 25.5 \\
17 & $(-40.2,25.68,-4.74)$ & Left inferior frontal gyrus (BA 47) & & \\
\hline
\end{tabular}

associated with schizophrenia not bipolar disorder (Harvey et al., 1994; Pearlson et al., 1997; Zipursky et al., 1997; Hirayasu et al., 2001; McDonald et al., 2005). In the intervening period, the advent of voxel-based techniques has expanded the literature on bipolar disorder. Our finding that gray matter deficits were rather more extensive in schizophrenia than bipolar disorder is in keeping with the classical observation that clinical prognosis for schizophrenia is better in the presence of affective symptoms. We generally concur with the previous study from Ellison-Wright and Bullmore (2010) that gray matter deficits identified in bipolar disorder are more restricted in extent compared to schizophrenia. However we noted that gray matter deficits in anterior cingulate cortex, a component of the limbic system and reward-learning pathway, were present in both disorders and not only in bipolar disorder. In addition we were intrigued to find caudate head volumetric deficits in both disorders but caudate tail enlargement in the bipolar group; in 
Table 3 | Percentage distribution of significant ALE clusters by disorder in enlarged gray matter volume.

\begin{tabular}{|c|c|c|c|c|}
\hline Cluster & $\begin{array}{l}\text { Cluster } \\
\text { center }\end{array}$ & Location & $\begin{array}{l}\text { Bipolar } \\
(\%)\end{array}$ & $\begin{array}{l}\text { Schizophrenia } \\
(\%)\end{array}$ \\
\hline 1 & $\begin{array}{l}(-27.32 \\
-2.97,12.47)\end{array}$ & $\begin{array}{l}\text { Left lentiform } \\
\text { nucleus }\end{array}$ & 12.8 & 87.2 \\
\hline 2 & $\begin{array}{l}(-23.84 \\
-7.92,-5.84)\end{array}$ & Left putamen & 46 & 54 \\
\hline 3 & $\begin{array}{l}(-8.29 \\
-0.87,-1.95)\end{array}$ & $\begin{array}{l}\text { Left globus } \\
\text { pallidus }\end{array}$ & 99.7 & 0.3 \\
\hline 4 & $\begin{array}{l}(-11.21 \\
-25.98,22.26)\end{array}$ & $\begin{array}{l}\text { Left caudate } \\
\text { (caudate tail) }\end{array}$ & 100 & 0 \\
\hline 5 & $\begin{array}{l}(12.83 \\
-26.57,22.13)\end{array}$ & $\begin{array}{l}\text { Right caudate } \\
\text { (caudate tail) }\end{array}$ & 100 & 0 \\
\hline 6 & $\begin{array}{l}(40.45 \\
-17.12,28.54)\end{array}$ & $\begin{array}{l}\text { Right pre/post-central } \\
\text { gyrus (BA4/BA6) }\end{array}$ & 100 & 0 \\
\hline
\end{tabular}

contrast, Ellison-Wright and Bullmore's (2010) reported overall caudate nucleus enlargement in the schizophrenia group only and other meticulous studies have shown no difference in caudate nucleus volume between patients with schizophrenia and healthy controls (Crespo-Facorro et al., 2007). The lower caudate volumes revealed in this study may be explained by the large number of first-episode studies included. In the schizophrenia literature, there is a reasonable consensus that caudate volumes are lower prior to drug treatment (Chua et al., 2007; Leung et al., 2009) but increase following even short periods of treatment (Chua et al., 2009; Deng et al., 2009).

Cincotta and Seger (2007) have reported that the caudate nucleus shows functional dissociation, with the caudate head mainly responsible for feedback processing whereas the caudate body and tail is involved in stimulus-category learning. Since the caudate head is linked to the dorsolateral prefrontal cortex while the ventral caudate body and tail are linked to the extrastriate and visual infero-temporal cortex, there should be caudate dissociation between frontal-executive learning and visual processing (Seger and Cincotta, 2006). If so then caudate head lesions may impact on motivational and learning skills which are present in both schizophrenia and bipolar disorder. However, we still do not know whether functional dissociation translates into structural morphology, thus further work on the role of the caudate in psychosis is much needed.

Right insula volumes were lower in both patients with schizophrenia and bipolar disorder, whereas lower left insula volumes were largely associated with schizophrenia. This result agrees with a number of ROI studies observing lower insular volumes in the left hemisphere (Caligiuri et al., 1993) and bilaterally (Graybiel, 1997; Kasparek et al., 2007) in schizophrenia. In contrast, the volume of insular cortex has been reported as unchanged in bipolar illness (Takahashi et al., 2009), but negatively correlated with number of depressive episodes suffered by these patients (Takahashi et al., 2010). Our results indicate that lower insula volumes in the left hemisphere may be more a feature of schizophrenia, while right hemispheric insula differences are found in both schizophrenia and bipolar disorder. Thus volume deficit of the insula may be preferentially linked to psychosis which appears consistent with studies showing negative correlation between insular volumes and psychotic symptoms (Caligiuri et al., 1993; Corson et al., 1999; Hurlemann et al., 2008).

Although we noted bilaterally located deficits in the schizophrenia group, those which were almost exclusively pertinent to the disorder were left lateralized. There is evidence that left-sided pathology in schizophrenia starts early, as it is reported even in adolescent onset schizophrenia (Janssen et al., 2008). Moreover left-sided pathology in frontal and temporal lobes may be progressive (Kasai et al., 2003; van Haren et al., 2007). In Crow's (1997b) essay on schizophrenia, he recognized schizophrenia as a disorder affecting both hemispheres and constraining typical left lateralization of brain (Crow, 1997b). A breakdown in the bi-hemispheric co-ordination of language is postulated to contribute to the nuclear symptoms of schizophrenia (Crow, 1997a,b; DeLisi et al., 1997), for example where disruption of communication between two hemispheres could be perceived as "voices" (Jaynes, 1990). The bihemispheric distribution of gray matter abnormalities in the studies reviewed fits the hypothesis that the processes driving asymmetry of the brain are interrupted in schizophrenia.

The current pattern of results therefore indicates that schizophrenia and bipolar disorders are not completely dichotomous entities at least at the level of neuroanatomical phenotype. This observation is necessarily simplistic, but lends further support to the argument that they share biological dimensions. It is compatible with Kraepelin's own qualification that it can sometimes be hard to stake out a firm diagnosis (Kraepelin, 1920). We welcome the renewed debate on diagnostic classification which can stimulate investigation of shared etiological mechanisms, and support the use of prognostic indicators and treatment targets relevant to both conditions. In terms of etiology, a recent very large scale study of families with members suffering from schizophrenia or bipolar disorder provided the strongest evidence to date that these disorders share a genetic basis (Lichtenstein et al., 2009). This agrees with accumulating evidence that schizophrenia and bipolar disorder have common susceptibility genes including 22q11, neuregulin 1, and transcription factor SP4 (Shifman et al., 2004; Green et al., 2005; Zhou et al., 2009). The disorders even have common prognostic indicators such as cognitive impairment (Green, 2006). The shared prefrontal cortical gray matter deficits observed here may well contribute to core common cognitive dysfunction leads to adverse effects on outcome in both disorders (Green, 2006).

Given these shared profiles, it is rather more challenging to explain why neuroanatomical differences are more extensive in schizophrenia than in bipolar disorder. Broadly speaking this could be a consequence of additional pathological mechanisms operating in schizophrenia, protective mechanisms at play in bipolar disorder, or some mixture of the two. The explanation for common and distinct neuroanatomy in schizophrenia and bipolar disorder is therefore likely to be complex. It is now better appreciated that even within one susceptibility gene such as DISC1 (Disrupted in schizophrenia 1), the risk of psychosis 
depends on one risk variant, in concert with other risk variants on the same gene (Hennah et al., 2009). The authors of this latter study concluded that "a new level of analysis is needed to take into account the stratification of genetic risk and the complexity of phenotypic association."

We acknowledge that our study has a number of methodological limitations. In general, studies reporting null results are less likely to be available and unfortunately, even if such information is accessible, ALE cannot accommodate "absent" foci. In addition, voxelbased methodology is continually being adapted and the data from original studies incorporated into our analysis most certainly had been preprocessed and analyzed in different ways (Fox et al., 2005; Honea et al., 2005; Laird et al., 2005; Ellison-Wright and Bullmore, 2009; Fornito et al., 2009). Unfortunately we did not have sufficient studies to control for such confounds as modulation and smoothing, and add our voice to the call for more "rigorous standards of data reporting” (Fox et al., 2005; Fornito et al., 2009).

\section{REFERENCES}

Adler, C. M., DelBello, M. P., Jarvis, K., Levine, A., Adams, J., and Strakowski, S. M. (2007). Voxel-based study of structural changes in first-episode patients with bipolar disorder. Biol. Psychiatry 61, 776-781.

Adler, C. M., Levine, A. D., DelBello, M. P., and Strakowski, S. M. (2005). Changes in gray matter volume in patients with bipolar disorder. Biol. Psychiatry 58, 151-157.

Almeida, J. R., Akkal, D., Hassel, S., Travis, M. J., Banihashemi, L., Kerr, N., Kupfer, D. J., and Phillips, M. L. (2009). Reduced gray matter volume in ventral prefrontal cortex but not amygdala in bipolar disorder: significant effects of gender and trait anxiety. Psychiatry Res. 171, 54-68.

Altshuler, L. L., Bartzokis, G., Grieder, T., Curran, J., Jimenez, T., Leight, K., Wilkins, J., Gerner, R., and Mintz, J. (2000). An MRI study of temporal lobe structures in men with bipolar disorder or schizophrenia. Biol. Psychiatry 48, 147-162.

Ananth, H., Popescu, I., Critchley, H. D., Good, C. D., Frackowiak, R. S., and Dolan, R. J. (2002). Cortical and subcortical gray matter abnormalities in schizophrenia determined through structural magnetic resonance imaging with optimized volumetric voxelbased morphometry. Am. J. Psychiatry 159, 1497-1505.

Angst, J., and Gamma, A. (2008). Diagnosis and course of affective psychoses: was Kraepelin right? Eur. Arch. Psychiatry Clin. Neurosci. 258(Suppl. 2), 107-110.

Antonova, E., Kumari, V., Morris, R., Halari, R., Anilkumar, A., Mehrotra, R., and Sharma, T. (2005). The relationship of structural alterations to cognitive deficits in schizophrenia: a voxel-based morphometry study. Biol. Psychiatry 58, 457-467.

Arnone, D., Cavanagh, J., Gerber, D. Lawrie, S. M., Ebmeier, K. P., and McIntosh, A. M. (2009). Magnetic resonance imaging studies in bipolar disorder and schizophrenia: meta-analysis. Br. J. Psychiatry 195, 194-201.

Bachmann, R. F., Schloesser, R. J., Gould, T. D., and Manji, H. K. (2005). Mood stabilizers target cellular plasticity and resilience cascades: implications for the development of novel therapeutics. Mol. Neurobiol. 32, 173-202.

Bassitt, D. P., Neto, M. R., de Castro, C. C., and Busatto, G. F. (2007). Insight and regional brain volumes in schizophrenia. Eur. Arch. Psychiatry Clin. Neurosci. 257, 58-62.

Benedetti, F., Bernasconi, A., Bosia, M., Cavallaro, R., Dallaspezia, S., Falini, A., Poletti, S., Radaelli, D., Riccaboni, R., Scotti, G., and Smeraldi, E. (2009). Functional and structural brain correlates of theory of mind and empathy deficits in schizophrenia. Schizophr. Res. 114, 154-160.

Berrettini,W. (2003). Bipolar disorder and schizophrenia: not so distant relatives? World Psychiatry 2, 68-72.

Bora, E., Fornito, A., Yucel, M., and Pantelis, C. (2010). Voxelwise metaanalysis of gray matter abnormalities in bipolar disorder. Biol. Psychiatry 67, 1097-1105.

Bora, E., Yucel, M., and Pantelis, C. (2009). Theory of mind impairment: a distinct trait-marker for schizophrenia spectrum disorders and bipolar disorder? Acta Psychiatr. Scand. 120, 253-264.

Bruno, S. D., Barker, G. J., Cercignani, M. Symms, M., and Ron, M. A. (2004). A study of bipolar disorder using magnetization transfer imaging and

In conclusion, we find that a synthesis of available data supports a number of shared neuroanatomical features of schizophrenia and bipolar disorder. This application of a technique which accommodates multiple studies in a relatively unbiased approach, serves to contribute additional information from neuroimaging research to the continuing debate on the Kraepelinian legacy. The results lend support to the proposition by van Os and Kapur (2009) that in schizophrenia what is inherited is "altered brain development, shared partly with ......affective disorders."

\section{ACKNOWLEDGMENTS}

The authors declare no conflict of interest, financial or otherwise arises from this work. We wish to thank the original ALE team and $\mathrm{CSL}^{1}$ for introducing this instrument to the research community.

${ }^{1} \mathrm{http}: / /$ csl.georgetown.edu/software

voxel-based morphometry. Brain 127 , 2433-2440.

Caligiuri, M. P., Lohr, J. B., and Jeste, D. V. (1993). Parkinsonism in neurolepticnaive schizophrenic patients. Am. J. Psychiatry 150, 1343-1348.

Cascella, N. G., Fieldstone, S. C., Rao, V.A. Pearlson, G. D, Sawa, A., and Schretlen, D. J. (2010). Gray-matter abnormalities in deficit schizophrenia. Schizophr. Res. 120, 63-70.

Chan, R. C., Di, X., McAlonan, G. M., and Gong, Q. Y. (2009). Brain anatomical abnormalities in high-risk individuals, first-episode, and chronic schizophrenia: an activation likelihood estimation meta-analysis of illness progression. Schizophr Bull. (http://schizophreniabulletin.oxfordjournals.org/content/ early/2009/07/24/schbul.sbp073.long)

Chen, X., Wen, W., Malhi, G. S., Ivanovski, B., and Sachdev, P. S. (2007). Regional gray matter changes in bipolar disorder: a voxel-based morphometric study. Aust. N. Z. J. Psychiatry 41, 327-336.

Chua, S. E., Cheung, C., Cheung, V., Tsang, J. T., Chen, E. Y., Wong, J. C., Cheung, J. P., Yip, L., Tai, K. S., Suckling, J., and McAlonan, G. M. (2007). Cerebral grey, white matter and csf in nevermedicated, first-episode schizophrenia. Schizophr. Res. 89, 12-21.

Chua, S. E., Deng, Y., Chen, E. Y., Law, C. W., Chiu, C. P., Cheung, C., Wong, J. C., Lienenkaemper, N., Cheung, V., Suckling, J., and McAlonan, G. M. (2009). Early striatal hypertrophy in first-episode psychosis within 3 weeks of initiating antipsychotic drug treatment. Psychol. Med. 39, 793-800.

Chua, S. E., and McKenna, P. J. (1995). Schizophrenia - a brain disease? A critical review of structural and functional cerebral abnormality in the disorder. Br. J. Psychiatry 166, 563-582.
Cincotta, C. M., and Seger, C. A. (2007). Dissociation between striatal regions while learning to categorize via feedback and via observation. J. Cogn. Neurosci. 19, 249-265.

Cooke, M. A., Fannon, D., Kuipers, E., Peters, E., Williams, S. C., and Kumari, V. (2008). Neurological basis of poor insight in psychosis: a voxel-based MRI study. Schizophr. Res. 103, 40-51.

Corson, P. W., Nopoulos, P., Andreasen, N. C., Heckel, D., and Arndt, S. (1999). Caudate size in first-episode neuroleptic-naive schizophrenic patients measured using an artificial neural network. Biol. Psychiatry 46, 712-720.

Crespo-Facorro, B., Kim, J., Andreasen, N. C., O'Leary, D. S., Bockholt, H. J., and Magnotta, V. (2000). Insular cortex abnormalities in schizophrenia: a structural magnetic resonance imaging study of first-episode patients. Schizophr. Res. 46, 35-43.

Crespo-Facorro, B., Roiz-Santianez, R., Pelayo-Teran, J. M., Gonzalez-Blanch, C., Perez-Iglesias, R., Gutierrez, A., de Lucas, E. M., Tordesillas, D., and Vazquez-Barquero, J. L. (2007). Caudate nucleus volume and its clinical and cognitive correlations in first episode schizophrenia. Schizophr. Res. 91, 87-96.

Crow, T. J. (1997a). Is schizophrenia the price that Homo sapiens pays for language? Schizophr. Res. 28, 127-141.

Crow, T. J. (1997b). Schizophrenia as failure of hemispheric dominance for language. Trends Neurosci. 20, 339-343.

DeLisi, L. E., Sakuma, M., Kushner, M., Finer, D. L., Hoff, A. L., and Crow, T. J. (1997). Anomalous cerebral asymmetry and language processing in schizophrenia. Schizophr. Bull. 23, 255-271. 
Deng, M.Y., McAlonan, G. M., Cheung, C., Chiu, C.P.,Law,C.W.,Cheung,V.,Sham, P.C., Chen, E.Y., and Chua, S.E. (2009). A naturalistic study of grey matter volume increase after early treatment in anti-psychotic naive, newly diagnosed schizophrenia. Psychopharmacology (Berl.) 206, 437-446.

Dickstein, D. P., Milham, M. P., Nugent, A. C., Drevets, W. C., Charney, D. S., Pine, D. S., and Leibenluft, E. (2005). Frontotemporal alterations in pediatric bipolar disorder: results of a voxel-based morphometry study. Arch. Gen. Psychiatry 62, 734-741.

Doris, A., Belton, E., Ebmeier, K. P., Glabus, M. F., and Marshall, I. (2004). Reduction of cingulate gray matter density in poor outcome bipolar illness. Psychiatry Res. 130, 153-159.

Douaud, G., Smith, S., Jenkinson, M., Behrens, T., Johansen-Berg, H., Vickers, J., James, S., Voets, N., Watkins, K., Matthews, P. M., and James, A. (2007). Anatomically related grey and white matter abnormalities in adolescent-onset schizophrenia. Brain 130, 2375-2386.

Drevets, W.C., Price, J.L., Simpson, J. R. Jr., Todd, R. D., Reich, T., Vannier, M., and Raichle, M. E. (1997). Subgenual prefrontal cortex abnormalities in mood disorders. Nature 386, 824-827.

Du, J., Gould, T. D. and Manji, H. K. (2003) "Neurotrophic signaling in mood disorders," in Signal Transduction and Human Disease, eds T. Finkel and J. S. Gutkind (Hoboken, NJ, USA: John Wiley \& Sons, Inc.). doi: 10.1002/0471482706.ch13

Ellison-Wright, I., and Bullmore, E. (2009). Meta-analysis of diffusion tensor imaging studies in schizophrenia. Schizophr. Res. 108, 3-10.

Ellison-Wright, I., and Bullmore, E. (2010). Anatomy of bipolar disorder and schizophrenia: a meta-analysis. Schizophr. Res. 117, 1-12.

Ellison-Wright, I., Glahn, D. C., Laird, A. R., Thelen, S. M., and Bullmore, E. (2008). The anatomy of firstepisode and chronic schizophrenia: an anatomical likelihood estimation meta-analysis. Am. J. Psychiatry 165, 1015-1023.

Euler, M., Thoma, R. J., Gangestad, S. W., Canive, J. M., and Yeo, R. A. (2009). The impact of developmental instability on Voxel-Based Morphometry analyses of neuroanatomical abnormalities in schizophrenia. Schizophr. Res. 115, 1-7.

Farrow, T. F., Whitford, T. J., Williams, L. M., Gomes, L., and Harris, A. W. (2005). Diagnosis-related regional gray matter loss over two years in first episode schizophrenia and bipolar disorder. Biol. Psychiatry 58, 713-723.
Fornito, A., Yucel, M., Patti, J., Wood, S. J., and Pantelis, C. (2009). Mapping grey matter reductions in schizophrenia: an anatomical likelihood estimation analysis of voxel-based morphometry studies. Schizophr. Res. 108, 104-113.

Fox, P. T., Laird, A. R., and Lancaster, J. L. (2005). Coordinate-based voxel-wise meta-analysis: dividends of spatial normalization. Report of a virtual workshop. Hum. Brain Mapp. 25, 1-5.

Friedman, L., Findling, R. L., Kenny, J. T., Swales, T. P., Stuve, T. A., Jesberger, J. A., Lewin, J.S., and Schulz, S. C. (1999). An MRI study of adolescent patients with either schizophrenia or bipolar disorder as compared to healthy control subjects. Biol. Psychiatry 46, $78-88$.

Garcia-Marti, G., Aguilar, E. J., Lull, J. J., Marti-Bonmati, L., Escarti, M. J., Manjon, J.V., Moratal, D., Robles, M., and Sanjuan, J. (2008). Schizophrenia with auditory hallucinations: a voxel-based morphometry study. Prog. Neuropsychopharmacol. Biol. Psychiatry 32, 72-80.

Giuliani, N. R., Calhoun, V. D., Pearlson, G. D., Francis, A., and Buchanan, R. W. (2005). Voxel-based morphometry versus region of interest: a comparison of two methods for analyzing gray matter differences in schizophrenia. Schizophr. Res. 74, 135-147.

Graybiel, A. M. (1997). The basal ganglia and cognitive pattern generators. Schizophr. Bull. 23, 459-469.

Green, E. K., Raybould, R., Macgregor, S., Gordon-Smith, K., Heron, J., Hyde, S., Grozeva, D., Hamshere, M., Williams, N., Owen, M. J., O’Donovan, M. C., Jones, L., Jones, I., Kirov, G., and Craddock, N. (2005). Operation of the schizophrenia susceptibility gene, neuregulin 1 , across traditional diagnostic boundaries to increase risk for bipolar disorder. Arch. Gen. Psychiatry 62, 642-648.

Green, M. F. (2006). Cognitive impairment and functional outcome in schizophrenia and bipolar disorder. $J$. Clin. Psychiatry 67:e12.

Gur, R. E., Turetsky, B. I., Bilker, W. B., and Gur, R. C. (1999). Reduced gray matter volume in schizophrenia. Arch. Gen. Psychiatry 56, 905-911.

Ha, T. H., Ha, K., Kim, J. H., and Choi, J. E. (2009). Regional brain gray matter abnormalities in patients with bipolar II disorder: a comparison study with bipolar I patients and healthy controls. Neurosci. Lett. 456, 44-48.

Ha, T.H., Youn, T., Ha, K. S., Rho, K.S., Lee, J. M., Kim, I. Y., Kim, S. I., and Kwon, J. S. (2004). Gray matter abnormalities in paranoid schizophrenia and their clinical correlations. Psychiatry Res. $132,251-260$.

Haldane, M., Cunningham, G., Androutsos, C., and Frangou, S. (2008). Structural brain correlates of response inhibition in Bipolar Disorder I. J. Psychopharmacol. 22, 138-143.

Harvey, I., Persaud, R., Ron, M. A., Baker, G., and Murray, R. M. (1994) Volumetric MRI measurements in bipolars compared with schizophrenics and healthy controls. Psychol. Med. 24, 689-699.

Heckers, S. (2008). Making progress in schizophrenia research. Schizophr. Bull. 34, 591-594.

Hennah, W., Thomson, P., McQuillin, A., Bass, N., Loukola, A., Anjorin, A., Blackwood, D., Curtis, D., Deary, I. J., Harris, S. E., Isometsa, E. T., Lawrence, J., Lonnqvist, J., Muir, W., Palotie, A., Partonen, T., Paunio, T., Pylkko, E. Robinson, M., Soronen, P., Suominen, K., Suvisaari, J., Thirumalai, S., St Clair D., Gurling, H., Peltonen, L., and Porteous, D. (2009). DISC1 association, heterogeneity and interplay in schizophrenia and bipolar disorder. Mol. Psychiatry 14, 865-873.

Herold, R., Feldmann, A., Simon, M., Tenyi, T., Kover, F., Nagy, F., Varga, E., and Fekete, S. (2009). Regional gray matter reduction and theory of mind deficit in the early phase of schizophrenia: a voxel-based morphometric study. Acta Psychiatr. Scand. 119 199-208.

Hirao, K., Miyata, J., Fujiwara, H., Yamada, M., Namiki, C., Shimizu, M., Sawamoto, N., Fukuyama, H. Hayashi, T., and Murai, T. (2008). Theory of mind and frontal lobe pathology in schizophrenia: a voxelbased morphometry study. Schizophr. Res. 105, 165-174.

Hirayasu, Y., Tanaka, S., Shenton, M. E., Salisbury, D. F., DeSantis, M. A., Levitt, J. J., Wible, C., YurgelunTodd, D., Kikinis, R., Jolesz, F. A., and McCarley, R. W. (2001). Prefrontal gray matter volume reduction in first episode schizophrenia. Cereb. Cortex 11,374-381.

Honea, R., Crow, T.J., Passingham, D., and Mackay, C.E. (2005). Regional deficits in brain volume in schizophrenia: a meta-analysis of voxel-based morphometry studies. Am. J. Psychiatry 162, 2233-2245.

Hulshoff Pol,H.E., Schnack, H. G., Mandl, R. C., van Haren, N. E., Koning, H. Collins, D. L., Evans, A. C., and Kahn, R.S. (2001). Focal gray matter density changes in schizophrenia. Arch. Gen. Psychiatry 58, 1118-1125.

Hurlemann, R., Matusch, A., Kuhn, K. U., Berning, J., Elmenhorst, D., Winz, O.
Kolsch, H.,Zilles, K., Wagner,M.,Maier, W., and Bauer, A. (2008). 5-HT2A receptor density is decreased in the atrisk mental state. Psychopharmacology (Berl.) 195, 579-590.

International Schizophrenia Consortium, Purcell, S. M., Wray, N. R., Stone, J. L., Visscher, P. M., O’Donovan, M. C., Sullivan, P. F., and Sklar, P. (2009). Common polygenic variation contributes to risk of schizophrenia and bipolar disorder. Nature 460, 748-752.

Janssen, J., Reig, S., Parellada, M., Moreno, D., Graell, M., Fraguas, D., Zabala, A., Garcia Vazquez, V., Desco, M., and Arango, C. (2008). Regional gray matter volume deficits in adolescents with first-episode psychosis. J. Am. Acad. Child Adolesc. Psychiatry 47, 1311-1320.

Jayakumar, P. N., Venkatasubramanian, G., Gangadhar, B. N., Janakiramaiah, N., and Keshavan, M. S. (2005). Optimized voxel-based morphometry of gray matter volume in first-episode, antipsychotic-naive schizophrenia. Prog. Neuropsychopharmacol. Biol. Psychiatry 29, 587-591.

Jaynes, P. K. (1990). Abbott spectrum design flaw allows the mismatching of patients' results. Clin. Chem. 36, 1702 .

Job, D. E., Whalley, H. C., McConnell, S., Glabus, M., Johnstone, E. C., and Lawrie, S. M. (2002). Structural gray matter differences between first-episode schizophrenics and normal controls using voxel-based morphometry. Neuroimage 17, 880-889.

Joyal, C. C., Laakso, M. P., Tiihonen, J., Syvalahti, E., Vilkman, H., Laakso, A., Alakare, B., Rakkolainen, V. Salokangas, R. K., and Hietala, J. (2003). The amygdala and schizophrenia: a volumetric magnetic resonance imaging study in first-episode, neuroleptic-naive patients. Biol. Psychiatry 54, 1302-1304.

Kasai, K., Shenton, M. E., Salisbury, D. F., Onitsuka, T., Toner, S. K., YurgelunTodd, D., Kikinis, R., Jolesz, F. A., and McCarley, R. W. (2003). Differences and similarities in insular and temporal pole MRI gray matter volume abnormalities in first-episode schizophrenia and affective psychosis. Arch. Gen. Psychiatry 60, 1069-1077.

Kasparek, T., Marecek, R., Schwarz, D., Prikryl, R., Vanicek, J., Mikl, M., and Ceskova,E. (2010). Source-based morphometry of gray matter volume in men with first-episode schizophrenia. Hum. Brain Mapp. 31, 300-310.

Kasparek, T., Prikryl, R., Mikl, M., Schwarz, D., Ceskova, E., and Krupa, P. (2007). Prefrontal but not temporal grey matter changes in males with first-episode schizophrenia. 
Prog. Neuropsychopharmacol. Biol. Psychiatry 31, 151-157.

Kawasaki, Y., Suzuki, M., Kherif, F., Takahashi, T., Zhou, S. Y., Nakamura, K., Matsui, M., Sumiyoshi, T., Seto, H., and Kurachi, M. (2007). Multivariate voxel-based morphometry successfully differentiates schizophrenia patients from healthy controls. Neuroimage 34, 235-242.

Kempton, M. J., Haldane, M., Jogia, J., Grasby, P. M., Collier, D., and Frangou, S. (2009). Dissociable brain structural changes associated with predisposition, resilience, and disease expression in bipolar disorder. $J$. Neurosci. 29, 10863-10868.

Koutsouleris, N., Gaser, C., Jager, M., Bottlender, R., Frodl, T., Holzinger, S., Schmitt, G. J., Zetzsche, T., Burgermeister, B., Scheuerecker, J., Born, C., Reiser, M., Moller, H. J., and Meisenzahl, E. M. (2008). Structural correlates of psychopathological symptom dimensions in schizophrenia: a voxel-based morphometric study. Neuroimage 39, 1600-1612.

Kraepelin. E. (1920). "Die Erscheinungsformen des Irresciens," in Themes and Variations in European Psychiatry, eds S. R. Hirsch and M. Shephred (Bristol: Wright), 7-30.

Kubicki, M., Shenton, M. E., Salisbury, D. F., Hirayasu, Y., Kasai, K., Kikinis, R., Jolesz, F. A., and McCarley, R. W. (2002). Voxel-based morphometric analysis of gray matter in first episode schizophrenia. Neuroimage 17, 1711-1719.

Laird, A. R., Eickhoff, S. B., Kurth, F., Fox, P. M., Uecker, A. M., Turner, J. A., Robinson, J. L., Lancaster, J. L., and Fox, P. T. (2009). ALE metaanalysis workflows via the brainmap database: progress towards a probabilistic functional brain atlas. Front. Neuroinformatics 3:23. doi: 10.3389/ neuro.11.023.2009.

Laird, A. R., Fox, P. M., Price, C. J., Glahn, D. C., Uecker, A. M., Lancaster, J. L., Turkeltaub, P. E., Kochunov, P., and Fox, P. T. (2005). ALE meta-analysis: controlling the false discovery rate and performing statistical contrasts. Hum. Brain Mapp. 25, 155-164.

Laird, A. R., Robinson, J. L., McMillan, K. M., Tordesillas-Gutierrez, D., Moran, S. T., Gonzales, S. M., Ray, K. L., Franklin, C., Glahn, D. C., Fox, P. T., and Lancaster,J.L. (2010).Comparison of the disparity between Talairach and MNI coordinates in functional neuroimaging data: validation of the Lancaster transform. Neuroimage 51, 677-683.

Leung, M., Cheung, C., Yu, K., Yip, B., Sham, P., Li, Q., Chua, S., and
McAlonan, G. (2009). Gray matter in first-episode schizophrenia before and after antipsychotic drug treatment. anatomical likelihood estimation meta-analyses with sample size weighting. Schizophr. Bull. (http:// schizophreniabulletin.oxfordjournals. org/content/early/2009/09/16/schbul. sbp099.long) for Leung et al., 2009.

Li, M., Cui, L., Deng, W., Ma, X., Huang, C., Jiang, L., Wang, Y., Collier, D., Gong, Q., and Li, T. (2010) Voxel-based morphometric analysis of the volume of gray matter in bipolar I disorder. Psychiatry Res. (in press).

Lichtenstein, P., Yip, B. H., Bjork, C., Pawitan, Y., Cannon, T. D., Sullivan, P. F., and Hultman, C. M. (2009). Common genetic determinants of schizophrenia and bipolar disorder in Swedish families: a population-based study. Lancet 373, 234-239.

Lim, K. O., Rosenbloom, M. J., Faustman, W. O., Sullivan, E.V., and Pfefferbaum, A. (1999). Cortical gray matter deficit in patients with bipolar disorder. Schizophr. Res. 40, 219-227.

Llewellyn, S. (2009). Is 'bipolar disorder' the brain's autopoietic response to schizophrenia? Med. Hypotheses 73 , 580-584.

Lochhead, R. A., Parsey, R. V., Oquendo, M. A., and Mann, J. J. (2004). Regional brain gray matter volume differences in patients with bipolar disorder as assessed by optimized voxel-based morphometry. Biol. Psychiatry 55, 1154-1162.

Lui, S., Deng, W., Huang, X., Jiang, L., Ma, X., Chen, H., Zhang, T., Li, X., Li, D., Zou, L., Tang, H., Zhou, X. J., Mechelli, A., Collier, D. A., Sweeney, J. A., Li, T., and Gong, Q. (2009a). Association of cerebral deficits with clinical symptoms in antipsychotic-naive firstepisode schizophrenia: an optimized voxel-based morphometry and resting state functional connectivity study. Am. J. Psychiatry 166, 196-205.

Lui, S., Deng, W., Huang, X., Jiang, L., Ouyang, L., Borgwardt, S. J., Ma, X., Li, D., Zou, L., Tang, H., Chen, H., Li, T., McGuire, P., and Gong, Q. (2009b). Neuroanatomical differences between familial and sporadic schizophrenia and their parents: an optimized voxelbased morphometry study. Psychiatry Res 171, 71-81.

Lyoo, I. K., Kim, M. J., Stoll, A. L., Demopulos, C. M., Parow, A. M., Dager, S. R., Friedman, S. D., Dunner, D. L., and Renshaw, P.F. (2004). Frontal lobe gray matter density decreases in bipolar I disorder. Biol. Psychiatry 55, 648-651.

Marcelis, M., Suckling, J., Woodruff, P., Hofman, P., Bullmore, E., and van
Os, J. (2003). Searching for a structural endophenotype in psychosis using computational morphometry. Psychiatry Res. 122, 153-167.

Marti-Bonmati, L., Lull, J. .., Garcia-Marti, G., Aguilar, E. J., Moratal-Perez, D. Poyatos, C., Robles, M., and Sanjuan, J. (2007). Chronic auditory hallucinations in schizophrenic patients: MR analysis of the coincidence between functional and morphologic abnormalities. Radiology 244, 549-556.

McCarley, R. W., Wible, C. G., Frumin, M., Hirayasu, Y., Levitt, J. J., Fischer, I. A., and Shenton, M. E. (1999). MRI anatomy of schizophrenia. Biol. Psychiatry 45, 1099-1119.

McDonald, C., Bullmore, E., Sham, P., Chitnis, X., Suckling, J., MacCabe, J., Walshe, M., and Murray, R. M. (2005). Regional volume deviations of brain structure in schizophrenia and psychotic bipolar disorder: computational morphometry study. $\mathrm{Br}$. J. Psychiatry 186, 369-377.

McIntosh, A. M., Job, D. E., Moorhead, T. W., Harrison, L. K., Forrester, K., Lawrie, S. M., and Johnstone, E. C. (2004). Voxel-based morphometry of patients with schizophrenia or bipolar disorder and their unaffected relatives. Biol. Psychiatry 56, 544-552.

McIntosh, A. M., Job, D. E., Moorhead, W. J., Harrison, L. K., Whalley, H. C., Johnstone, E. C., and Lawrie, S. M. (2006). Genetic liability to schizophrenia or bipolar disorder and its relationship to brain structure. Am. J. Med. Genet. B Neuropsychiatr. Genet. 141B, 76-83.

Meda, S. A., Giuliani, N. R., Calhoun, V. D., Jagannathan, K., Schretlen, D. J., Pulver, A., Cascella, N., Keshavan, M., Kates, W., Buchanan, R., Sharma, T., and Pearlson, G.D. (2008). A large scale $(\mathrm{N}=400)$ investigation of gray matter differences in schizophrenia using optimized voxel-based morphometry. Schizophr. Res. 101, 95-105.

Meisenzahl, E. M., Koutsouleris, N. Bottlender, R., Scheuerecker, J., Jager, M., Teipel, S. J., Holzinger, S., Frodl, T., Preuss, U., Schmitt, G., Burgermeister, B., Reiser, M., Born, C., and Moller, $\mathrm{H}$ J. (2008). Structural brain alterations at different stages of schizophrenia: a voxel-based morphometric study. Schizophr. Res. 104, 44-60.

Moore, G. J., Bebchuk, J. M., Wilds, I. B., Chen, G., and Manji, H. K. (2000). Lithium-induced increase in human brain grey matter. Lancet 356 , 1241-1242.

Moorhead, T. W., Job, D. E., Whalley, H. C., Sanderson, T. L., Johnstone, E. C., and Lawrie, S. M. (2004). Voxelbased morphometry of comorbid schizophrenia and learning disability: analyses in normalized and native spaces using parametric and nonparametric statistical methods. Neuroimage 22, 188-202.

Neckelmann, G., Specht, K., Lund, A., Ersland,L.,Smievoll,A.I.,Neckelmann, D., and Hugdahl, K. (2006). Mr morphometry analysis of grey matter volume reduction in schizophrenia: association with hallucinations. Int. J. Neurosci. 116, 9-23.

Nugent, A. C., Milham, M. P., Bain, E. E., Mah, L., Cannon, D. M., Marrett, S., Zarate, C. A., Pine, D. S., Price, J. L. and Drevets, W. C. (2006). Cortical abnormalities in bipolar disorder investigated with MRI and voxelbased morphometry. Neuroimage 30, 485-497.

Ohnishi, T., Hashimoto, R., Mori, T., Nemoto, K., Moriguchi, Y., Iida, H., Noguchi, H., Nakabayashi, T., Hori, H., Ohmori, M., Tsukue, R., Anami, K., Hirabayashi, N., Harada, S., Arima, K., Saitoh, O., and Kunugi, H. (2006). The association between the Val158Met polymorphism of the catechol-O-methyl transferase gene and morphological abnormalities of the brain in chronic schizophrenia. Brain 129, 399-410.

Paillere-Martinot, M., Caclin, A., Artiges, E., Poline, J. B., Joliot, M., Mallet, L., Recasens, C., Attar-Levy, D., and Martinot, J. L. (2001). Cerebral gray and white matter reductions and clinical correlates in patients with early onset schizophrenia. Schizophr. Res. 50, 19-26.

Pearlson, G. D., Barta, P. E., Powers, R. E., Menon, R. R., Richards, S. S., Aylward, E. H., Federman, E. B., Chase, G. A., Petty, R. G., and Tien, A. Y. (1997). Ziskind-Somerfeld Research Award 1996. Medial and superior temporal gyral volumes and cerebral asymmetry in schizophrenia versus bipolar disorder. Biol. Psychiatry 41, 1-14.

Prasad, K. M., Shirts, B. H., Yolken, R. H., Keshavan, M.S., and Nimgaonkar,V.L. (2007). Brain morphological changes associated with exposure to HSV1 in first-episode schizophrenia. Mol. Psychiatry 12, 105-113.

Salgado-Pineda, P., Baeza, I., PerezGomez, M., Vendrell, P., Junque, C. Bargallo, N., and Bernardo, M. (2003). Sustained attention impairment correlates to gray matter decreases in first episode neuroleptic-naive schizophrenic patients. Neuroimage 19, 365-375.

Salgado-Pineda, P., Junque, C., Vendrell, P., Baeza, I., Bargallo, N., Falcon, C., and Bernardo, M. (2004). Decreased cerebral activation during CPT performance: structural and functional 
deficits in schizophrenic patients. Neuroimage 21, 840-847.

Schaufelberger, M.S., Duran, F.L., Lappin, J. M., Scazufca, M., Amaro, E. Jr., Leite, C. C., de Castro, C. C., Murray, R. M., McGuire, P. K., Menezes, P. R., and Busatto, G. F. (2007). Grey matter abnormalities in Brazilians with firstepisode psychosis. Br. J. Psychiatry Suppl. 51, S117-S122.

Scherk, H., Kemmer, C., Usher, J., Reith, W., Falkai, P., and Gruber, O. (2008). No change to grey and white matter volumes in bipolar I disorder patients. Eur. Arch. Psychiatry Clin. Neurosci. 258, 345-349.

Segall, J. M., Turner, J. A., van Erp, T. G., White, T., Bockholt, H. J., Gollub, R. L., Ho, B. C., Magnotta, V., Jung, R. E., McCarley, R. W., Schulz, S. C., Lauriello, J., Clark, V. P., Voyvodic, J. T., Diaz, M. T., and Calhoun, V.D. (2009). Voxel-based morphometric multisite collaborative study on schizophrenia. Schizophr. Bull. 35, 82-95.

Seger, C. A., and Cincotta, C. M. (2006). Dynamics of frontal, striatal, and hippocampal systems during rule learning. Cereb. Cortex 16, 1546-1555.

Shao, L., and Vawter, M. P. (2008). Shared gene expression alterations in schizophrenia and bipolar disorder. Biol. Psychiatry 64, 89-97.

Shapleske, J., Rossell, S. L., Chitnis, X. A., Suckling, J., Simmons, A., Bullmore, E. T., Woodruff, P. W., and David, A. S. (2002). A computational morphometric MRI study of schizophrenia: effects of hallucinations. Cereb. Cortex 12, 1331-1341.

Shifman, S., Bronstein, M., Sternfeld, M., Pisante, A., Weizman, A., Reznik, I., Spivak, B., Grisaru, N., Karp, L., Schiffer, R., Kotler, M., Strous, R. D., Swartz-Vanetik, M., Knobler, H. Y., Shinar, E., Yakir, B., Zak, N. B., and Darvasi,A. (2004).COMT: a common susceptibility gene in bipolar disorder and schizophrenia. Am. J. Med. Genet. B Neuropsychiatr. Genet. 128B, 61-64.

Sigmundsson, T., Suckling, J., Maier, M., Williams, S., Bullmore, E., Greenwood, K., Fukuda, R., Ron, M., and Toone, B. (2001). Structural abnormalities in frontal, temporal, and limbic regions and interconnecting white matter tracts in schizophrenic patients with prominent negative symptoms. Am. J. Psychiatry 158, 234-243.

Silverstone, P. H., Wu, R. H., O'Donnell, T., Ulrich, M., Asghar,S.J., and Hanstock,C. C. (2003). Chronic treatment with lithium, but not sodium valproate, increases cortical N-acetyl-aspartate concentrations in euthymic bipolar patients. Int. Clin. Psychopharmacol. 18, 73-79.
Stanfield, A. C., Moorhead, T. W., Job, D. E., McKirdy, J., Sussmann, J. E., Hall, J., Giles, S., Johnstone, E. C., Lawrie, S. M., and McIntosh, A. M. (2009). Structural abnormalities of ventrolateral and orbitofrontal cortex in patients with familial bipolar disorder. Bipolar Disord. 11, 135-144.

Suzuki, M., Nohara, S., Hagino, H., Kurokawa, K., Yotsutsuji, T., Kawasaki, Y., Takahashi, T., Matsui, M., Watanabe, N., Seto, H., and Kurachi, M. (2002). Regional changes in brain gray and white matter in patients with schizophrenia demonstrated with voxelbased analysis of MRI. Schizophr. Res. 55, 41-54.

Takahashi, T., Malhi, G. S., Wood, S. J., Walterfang, M., Yucel, M., Lorenzetti, V., Soulsby, B., Suzuki, M., Velakoulis, D., and Pantelis, C. (2009). Increased pituitary volume in patients with established bipolar affective disorder. Prog. Neuropsychopharmacol. Biol. Psychiatry 33, 1245-1249.

Takahashi, T., Malhi, G.S., Wood,S.J.,Yucel, M., Walterfang, M., Tanino, R., Suzuki, M., and Pantelis, C. (2010). Insular cortex volume in established bipolar affective disorder: a preliminary MRI study. Psychiatry Res. 182, 187-190.

Talairach, J., and Tournoux, P. (1988). Co-Planar Stereotaxic Atlas of the Human Brain. New York: Thieme.

Tomelleri, L., Jogia, J., Perlini, C., Bellani, M., Ferro, A., Rambaldelli, G., Tansella, M., Frangou, S., and Brambilla, P. (2009). Brain structural changes associated with chronicity and antipsychotic treatment in schizophrenia. Eur. Neuropsychopharmacol. 19, 835-840.

Tost, H., Ruf, M., Schmal, C., Schulze, T. G., Knorr, C., Vollmert, C., Bosshenz, K., Ende, G., Meyer-Lindenberg, A., Henn, F. A., and Rietschel, M. (2010). Prefrontal-temporal gray matter deficits in bipolar disorder patients with persecutory delusions. J. Affect. Disord. 120, 54-61.

Tregellas, J. R., Shatti, S., Tanabe, J. L., Martin, L. F., Gibson, L., Wylie, K., and Rojas, D. C. (2007). Gray matter volume differences and the effects of smoking on gray matter in schizophrenia. Schizophr. Res. 97, 242-249.

Turkeltaub, P. E., Eden, G. F., Jones, K. M., and Zeffiro, T. A. (2002). Metaanalysis of the functional neuroanatomy of single-word reading: method and validation. Neuroimage $16,765-780$.

van Haren, N. E., Hulshoff Pol, H. E., Schnack, H. G., Cahn, W., Mandl, R. C., Collins, D. L., Evans, A. C., and
Kahn, R. S. (2007). Focal gray matter changes in schizophrenia across the course of the illness: a 5-year follow-up study. Neuropsychopharmacology 32, 2057-2066.

van Os, J., and Kapur, S. (2009). Schizophrenia. Lancet 374, 635-645.

Velakoulis, D., Pantelis, C., McGorry, P. D., Dudgeon, P., Brewer, W., Cook, M., Desmond, P., Bridle, N., Tierney, P., Murrie, V., Singh, B., and Copolov, D. (1999). Hippocampal volume in first-episode psychoses and chronic schizophrenia: a high-resolution magnetic resonance imaging study. Arch. Gen. Psychiatry 56, 133-141.

Venkatasubramanian, G. (2010). Neuroanatomical correlates of psychopathology in antipsychotic-naive schizophrenia. Indian J. Psychiatry 52, 28-36.

Venkatasubramanian, G., Jayakumar, P. N., Gangadhar, B. N., and Keshavan, M. S. (2008). Neuroanatomical correlates of neurological soft signs in antipsychotic-naive schizophrenia. Psychiatry Res. 164, 215-222.

Whitford, T. J., Grieve, S. M., Farrow, T. F., Gomes, L., Brennan, J., Harris, A. W., Gordon, E., and Williams, L. M. (2006). Progressive grey matter atrophy over the first 2-3 years of illness in first-episode schizophrenia: a tensor-based morphometry study. Neuroimage 32, 511-519.

Wilke, M., Kaufmann, C., Grabner, A., Putz, B., Wetter, T. C., and Auer, D. P. (2001). Gray matter-changes and correlates of disease severity in schizophrenia: a statistical parametric mapping study. Neuroimage 13 814-824.

Witthaus, H., Kaufmann, C., Bohner, G. Ozgurdal, S., Gudlowski, Y., Gallinat, J., Ruhrmann, S., Brune, M., Heinz, A., Klingebiel, R., and Juckel, G. (2009) Gray matter abnormalities in subjects at ultra-high risk for schizophrenia and first-episode schizophrenic patients compared to healthy controls. Psychiatry Res. 173, 163-169.

Wolf, R. C., Hose, A., Frasch, K., Walter, H., and Vasic, N. (2008). Volumetric abnormalities associated with cognitive deficits in patients with schizophrenia. Eur. Psychiatry 23, 541-548.

Wright, I. C., Ellison, Z. R., Sharma, T., Friston, K. J., Murray, R. M., and McGuire, P. K. (1999). Mapping of grey matter changes in schizophrenia. Schizophr. Res. 35, 1-14.

Wright, I.C., Rabe-Hesketh, S., Woodruff, P. W., David, A. S., Murray, R. M., and Bullmore, E. T. (2000). Metaanalysis of regional brain volumes in schizophrenia. Am. J. Psychiatry 157, 16-25.

Xu, L., Pearlson, G., and Calhoun, V. D. (2009). Joint source based morphometry identifies linked gray and white matter group differences. Neuroimage 44, 777-789.

Yamada, M., Hirao, K., Namiki, C., Hanakawa, T., Fukuyama, H., Hayashi, T., and Murai, T. (2007). Social cognition and frontal lobe pathology in schizophrenia: a voxel-based morphometric study. Neuroimage 35, 292-298.

Yatham, L. N., Lyoo, I. K., Liddle, P., Renshaw, P. F., Wan, D., Lam, R. W., and Hwang, J. (2007). A magnetic resonance imaging study of mood stabilizer- and neuroleptic-naive first-episode mania. Bipolar Disord. 9, 693-697.

Yoshihara, Y., Sugihara, G., Matsumoto, H., Suckling, J., Nishimura, K., Toyoda, T. Isoda, H., Tsuchiya, K. J., Takebayashi, K., Suzuki, K., Sakahara, H., Nakamura, K., Mori, N., and Takei, N. (2008). Voxel-based structural magnetic resonance imaging (MRI) study of patients with early onset schizophrenia. Ann Gen. Psychiatry 7, 25.

Zhou, X., Tang, W., Greenwood, T.A., Guo, S., He, L., Geyer, M. A., and Kelsoe, J. R. (2009). Transcription factor SP4 is a susceptibility gene for bipolar disorder. PLoS ONE 4:e5196.doi: 10.1371/ journal.pone.0005196.

Zipursky, R. B., Seeman, M. V., Bury, A., Langevin, R., Wortzman, G., and Katz, R. (1997). Deficits in gray matter volume are present in schizophrenia but not bipolar disorder. Schizophr. Res. 26, 85-92.

Conflict of Interest Statement: The authors declare that the research was conducted in the absence of any commercial or financial relationships that could be construed as a potential conflict of interest

Received: 31 May 2010; accepted: 22 September 2010; published online: 26 October 2010.

Citation: Yu K, Cheung C, Leung $M$, Li Q, Chua S and McAlonan G (2010) Are bipolar disorder and schizophrenia neuroanatomically distinct? An anatomical likelihood meta-analysis. Front. Hum. Neurosci. 4:189. doi: 10.3389/ fnhum.2010.00189

Copyright $\odot 2010$ Yu, Cheung, Leung, Li, Chua and McAlonan. This is an open-access article subject to an exclusive license agreement between the authors and the Frontiers Research Foundation, which permits unrestricted use, distribution, and reproduction in any medium, provided the original authors and source are credited. 